\title{
Overview of the Nordic Seas CARINA data and salinity measurements
}

\author{
A. Olsen ${ }^{1,2}$, R. M. Key ${ }^{3}$, E. Jeansson ${ }^{1}$, E. Falck ${ }^{4}$, J. Olafsson ${ }^{5}$, S. van Heuven ${ }^{6}$, I. Skjelvan ${ }^{1,4}$, \\ A. M. Omar ${ }^{1,4}$, K. A. Olsson ${ }^{2,1}$, L. G. Anderson ${ }^{2}$, S. Jutterström ${ }^{2}$, F. Rey ${ }^{7}$, T. Johannessen ${ }^{4,1}$, \\ R. G. J. Bellerby ${ }^{1,4}$, J. Blindheim ${ }^{7}$, J. L. Bullister ${ }^{8}$, B. Pfeil ${ }^{1}$, X. Lin $^{3}$, A. Kozyr ${ }^{9}$, C. Schirnick ${ }^{10}$, \\ T. Tanhua ${ }^{10}$, and D. W. R. Wallace ${ }^{10}$ \\ ${ }^{1}$ Bjerknes Centre for Climate Research, UNIFOB AS, Allegaten 55, 5007 Bergen, Norway \\ ${ }^{2}$ Department of Chemistry, University of Gothenburg, 41296 Göteborg, Sweden \\ ${ }^{3}$ Atmospheric and Oceanic Sciences Program, Princeton University, Princeton, NJ 08544, USA \\ ${ }^{4}$ Geophysical Institute, University of Bergen, Bergen, Norway \\ ${ }^{5}$ Faculty of Earth Sciences, University of Iceland and Marine Research Institute, Reykjavik, Iceland \\ ${ }^{6}$ Departement of Ocean Ecosystems, University of Groningen, Groningen, The Netherlands \\ ${ }^{7}$ Institute of Marine Research, Bergen, Norway \\ ${ }^{8}$ Pacific Marine Environmental Laboratory/NOAA, 7600 Sand Point Way NE, Seattle, WA 98115-6349, USA \\ ${ }^{9}$ Carbon Dioxide Information Analysis Center, Oak Ridge National Laboratory, Oak Ridge, TN 37831, USA \\ ${ }^{10}$ Leibniz-Institut für Meereswissenshaften, Marine Biogeochemie, Kiel, Germany
}

Received: 23 June 2009 - Published in Earth Syst. Sci. Data Discuss.: 3 July 2009

Revised: 4 November 2009 - Accepted: 6 November 2009 - Published: 19 November 2009

\begin{abstract}
Water column data of carbon and carbon relevant hydrographic and hydrochemical parameters from 188 previously non-publicly available cruises in the Arctic, Atlantic, and Southern Ocean have been retrieved and merged into a new database: CARINA (CARbon IN the Atlantic). The data have been subject to rigorous quality control (QC) in order to ensure highest possible quality and consistency. The data for most of the parameters included were examined in order to quantify systematic biases in the reported values, i.e. secondary quality control. Significant biases have been corrected for in the data products, i.e. the three merged files with measured, calculated and interpolated values for each of the three CARINA regions; the Arctic Mediterranean Seas (AMS), the Atlantic (ATL) and the Southern Ocean (SO). With the adjustments the CARINA database is consistent both internally as well as with GLODAP (Key et al., 2004) and is suitable for accurate assessments of, for example, oceanic carbon inventories and uptake rates and for model validation. The Arctic Mediterranean Seas include the Arctic Ocean and the Nordic Seas, and the quality control was carried out separately in these two areas. This contribution provides an overview of the CARINA data from the Nordic Seas and summarises the findings of the QC of the salinity data. One cruise had salinity data that were of questionable quality, and these have been removed from the data product. An evaluation of the consistency of the quality controlled salinity data suggests that they are consistent to at least \pm 0.005 .
\end{abstract}

\section{Data coverage and parameter measured}

Repository-Reference: doi:10.3334/CDIAC/otg.CARINA.AMS.V1.2 Available at: http://cdiac.ornl.gov/oceans/CARINA/Carina_inv.html
Coverage: $59.60^{\circ} \mathrm{N}-82.35^{\circ} \mathrm{N}, 35.23^{\circ} \mathrm{W}-28^{\circ} \mathrm{E}$

Location Name: Nordic Seas

Date/Time Start: 1982-02-28

Date/Time End: 2006-02-10

Correspondence to: A. Olsen

(are.olsen@gfi.uib.no)

Published by Copernicus Publications. 


\begin{tabular}{lllll}
\hline $\begin{array}{l}\text { Data Product } \\
\text { Parameter Name }\end{array}$ & $\begin{array}{l}\text { Data Product } \\
\text { Flag Name }\end{array}$ & $\begin{array}{l}\text { Exchange File } \\
\text { Parameter Name }\end{array}$ & $\begin{array}{l}\text { Exchange File } \\
\text { Flag Name }\end{array}$ & \\
\hline station & & STANBR & & \\
day & DATE & & \\
month & DATE & & decimal degrees \\
year & DATE & & decimal degrees \\
latitude & LATITUDE & & meters \\
$\begin{array}{l}\text { longitude } \\
\text { cruiseno }\end{array}$ & LONGITUDE & & \\
$\begin{array}{l}\text { depth } \\
\text { temperature }\end{array}$ & & & & \\
salinity & & CTDTMP & & \\
ctdsal & sf & SALNTY & SALNTY_FLAG_W & \\
pressure & ctdsf & CTDSAL & CTDSAL_FLAG_W & decibars \\
\hline
\end{tabular}

For a complete list of all parameters available in CARINA see Key et al. (2009). Note the different names for the parameters in the Exchange files (the individual cruise files) and the merged data product.

\section{Introduction}

CARINA (CARbon IN the Atlantic) is a database of carbon and carbon-relevant data from hydrographic cruises in the Arctic, Atlantic and Southern oceans. The project started as an essentially informal, unfunded project in Delmenhorst, Germany, in 1999 during the workshop on " $\mathrm{CO}_{2}$ in the North Atlantic", with the main goal to create a uniformly formatted database of carbon relevant variables in the ocean to be used for accurate assessments of oceanic carbon inventories and uptake rates. The collection of data and the quality control (QC) of the data have been a main focus of the CARINA project. Both primary and secondary QC of the data has been performed.

The CARINA database consists of two parts: the first part is the set of the individual cruise files where all the data reported by the measurement teams are stored. Quality flags are accompanying the data, in many cases these are the flags originally reported, in others they were assigned by R. M. Key. These files are in WHP (WOCE Hydrographic Program) exchange format where the first lines consist of the condensed metadata. There are essentially no calculated or interpolated values in the individual cruise files, with the exceptions of pressure calculated from depth and some bottle salinities that were taken from ctdsal. No adjustments have been applied to any of these values with the exception that all $\mathrm{pH}$ measurements were converted to the seawater $\mathrm{pH}$ scale at $25^{\circ} \mathrm{C}$ (Velo et al., 2009).

The second part of CARINA consists of three merged, quality controlled and adjusted data files; one each for the Atlantic Ocean, Arctic Mediterranean Seas and Southern Ocean regions. These files contain all the CARINA data and also include: 1) interpolated values for nutrients, oxygen and salinity if those data were missing and the interpolation could be made according to certain criteria, as described in Key et al. (2009); 2) calculated carbon parameters; e.g. if total dissolved inorganic carbon $\left(\mathrm{TCO}_{2}\right)$ and total alkalinity (TA) data were available, $\mathrm{pH}$ was calculated; and 3) instances where bottle salinity was missing or bad and was replaced with CTD salinity. Calculated or interpolated values have been given the quality flag " 0 ". In many cases there are additional parameters in the individual cruise files, which have not been included in the secondary QC, such as $\Delta^{14} \mathrm{C}, \delta^{13} \mathrm{C}$ and $\mathrm{SF}_{6}$. Most of these are included in the merged data files as well.

This report provides an overview of the Nordic Seas data in CARINA and summarises the results of the analysis of the salinity data from this region. These data are part of the Arctic Mediterranean Seas subset of CARINA (CARINA-AMS). This subset includes data from the Nordic Seas and the Arctic Ocean. Not one of the cruises of CARINA covered both the Arctic Ocean and the Nordic Seas to the extent that it could be included in the secondary quality control in both regions. In addition, the differences in data density in the two regions enforced the use of different QC methods for the data collected in them. The data from these regions were therefore analysed separately, and the data from the Arctic Ocean are described by Jutterström et al. (2009), whereas the Nordic Seas data are described here and in Olsen (2009a), Olsen (2009b), Falck and Olsen (2009), Jeansson et al. (2009), and Olafsson and Olsen (2009). A more comprehensive description of the complete CARINA database can be found in Key et al. (2009), as well as in the other, more specialised, papers in this special issue.

\section{Data provenance}

The Transient Tracers in the Ocean-North Atlantic Study (TTO-NAS, Brewer et al., 1986) carried out during summer of 1981 was the first cruise in the Nordic Seas in modern times where carbon chemistry data were collected. TTONAS is not officially a part of CARINA, but the data have been used to aid the $\mathrm{TCO}_{2}$ consistency analyses (Olsen, 2009a). TTO-NAS was followed by the CSS Hudson cruise 


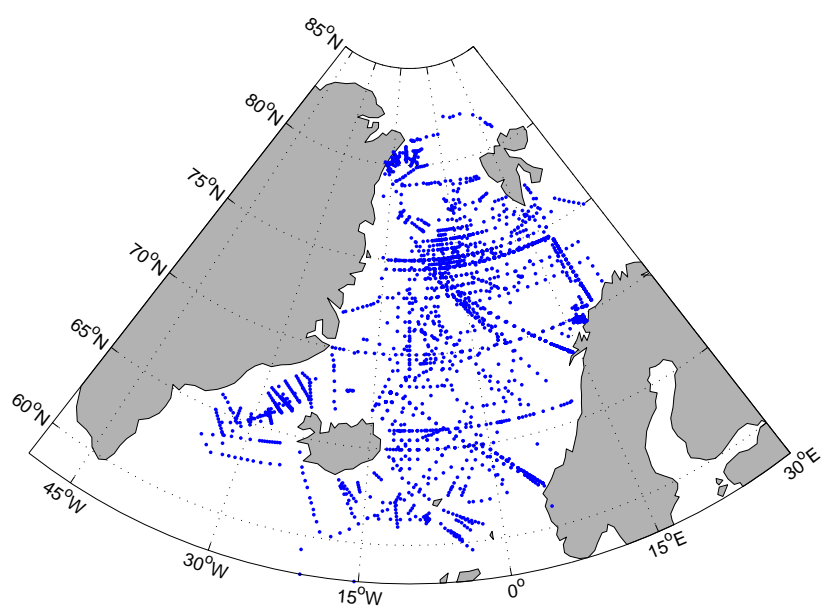

Figure 1. The Nordic Seas with the positions of CARINA data included in this region.

of winter 1982 (18HU19820228 (36), number in parenthesis is the CARINA cruise number), which is the oldest cruise with data from the Nordic Seas in CARINA. This cruise included sampling for $\mathrm{TCO}_{2}$, Total Alkalinity (TA), and chlorofluoro compounds (CFCs), in addition to standard variables like temperature, salinity, nutrients, and oxygen. After the CSS Hudson cruise no carbon data were collected in the Nordic Seas until the 1990s. Early that decade two important programs were initiated: (1) Sampling for CFCs at the repeated surveys of the Nordic Seas by the Institute of Marine Research (IMR) was started in 1991 (Bönisch et al., 1997; Karstensen et al., 2005) and (2) The ESOP and CARDEEP projects, funded in 1993 by the European Union and Norwegian Research Council, respectively. The two latter projects included a series of cruises with sampling for carbon chemistry and carbon-relevant data in the Nordic Seas for 3 years. Later, this activity was continued through the EU projects ESOP II and TRACTOR. These data are the backbone of the CARINA Nordic Seas data collection.

The Nordic Seas was loosely defined as the region closed by the Fram Strait to the north, Greenland to the west, the Greenland-Scotland Ridge to the south, and Norway, the Barents Sea Opening, and Spitsbergen to the east. Out of the 188 CARINA cruises, 62 are included in the CARINA-AMS, and 35 of these considered as Nordic Seas cruises. Five of these are in common with the Atlantic Ocean subset of CARINA (Tanhua et al., 2009b), in order to ensure consistency between the regions. The positions of the stations of the cruises that were included are shown in Fig. 1 and the cruises are listed in Table 1. Two of the entries in Table 1 are not single cruises, OMEX1NS (186) and Iceland Sea (184), but rather collections of data from more or less the same place from one (OMEX1NS (186)) or several years (Iceland Sea (184)). The sample distributions with time and latitude are shown in Fig. $2 a$ and $b$. These figures show only data that have been re-
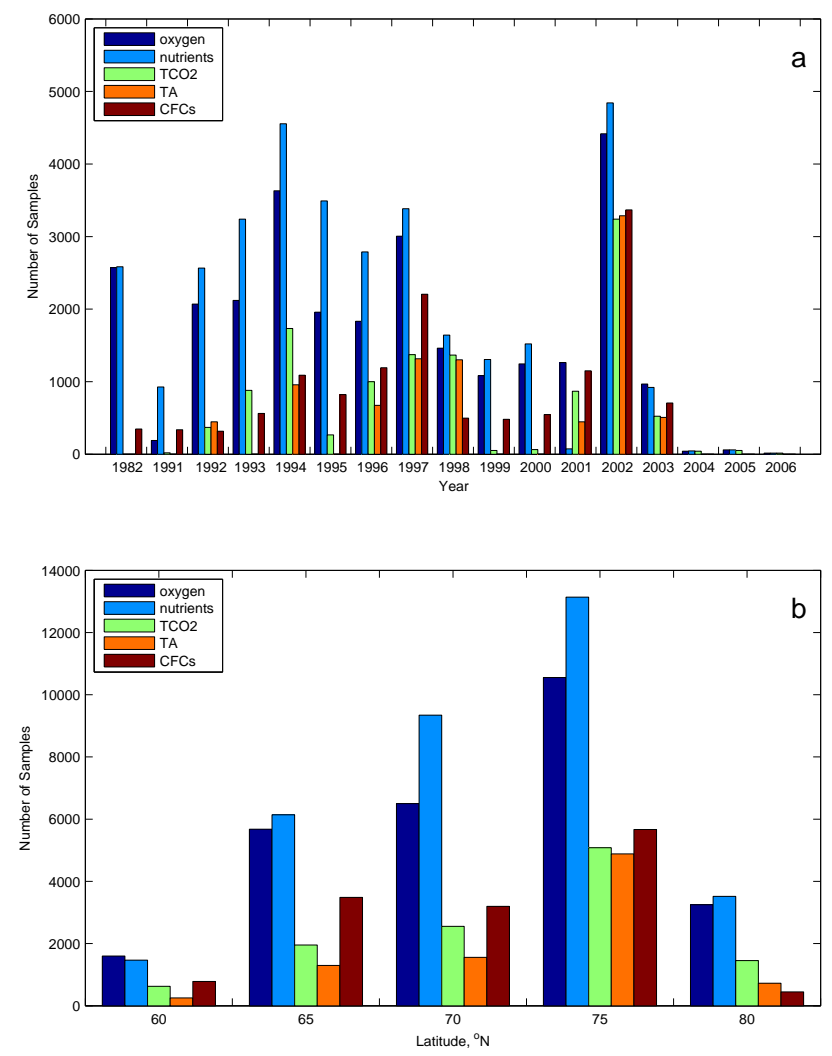

Figure 2. Data distribution of Nordic Seas CARINA data, number of samples by (a) year and (b) latitude, binned into $5^{\circ}$ latitude bands. Data that were found to be of too poor quality to be included in the CARINA product are not included. The count for nutrients reflects measurements of any or several of the triplet nitrate, phosphate, and silicate. Similarly, the count for CFC reflects measurements of any or several of CFC-11, CFC-12, CFC-113, and CCl4. Note that X-axis jumps from 1982 to 1991 in (a). Interpolated or calculated values have not been included.

tained after the secondary quality control was completed and do not include interpolated or calculated values. There are more than twice as many oxygen and nutrient data as $\mathrm{TCO}_{2}$ and TA, and there also tends to be more CFC samples. This is because the collection includes the IMR cruises with sampling for oxygen, nutrients and CFCs, but no carbon data. As the 1982 Hudson $\mathrm{TCO}_{2}$ and TA data were found to be of too poor quality to be included in the final CARINA product (Olsen, 2009a and b), the earliest carbon data are from 1991. Most data were collected in 2002 with the joint Oden/Knorr effort (Olsen et al., 2006; Jeansson et al., 2008; Jutterström et al., 2008). The most recent cruise data available are from 2003 , and it is only the Iceland Sea time series data which covers 2003-2006. The latitudinal distribution of the data reflects the emphasis on the Greenland Sea where, in particular, the section across $75^{\circ} \mathrm{N}$ has been occupied repeatedly. 
Table 1. CARINA cruises with data from the Nordic Seas. The table lists CARINA cruiseno., EXPOCODE, and recommendations from the secondary quality control. Apart from the NC (Not Considered), ND (No Data) and Flag 3 (questionable quality) entries, the numbers are the recommended adjustments. For salinity, $\mathrm{TCO}_{2}$ and TA these are additive, whereas those for oxygen, nutrients, and $\mathrm{CFCs}$ are multiplicative. Data of questionable quality (Flag 3 ) are not included in the merged data product.

\begin{tabular}{|c|c|c|c|c|c|c|c|c|c|c|c|c|c|}
\hline No & EXPOCODE & Salinity & $\mathrm{TCO}_{2}^{\mathrm{a}}$ & $\mathrm{TA}^{\mathrm{b}}$ & $\mathrm{pH}^{\mathrm{c}}$ & $\mathrm{NO}_{3}^{\mathrm{d}}$ & $\mathrm{PO}_{4}^{\mathrm{d}}$ & $\mathrm{Si}^{\mathrm{d}}$ & Oxygen $^{e}$ & $\mathrm{CFC} 11^{\mathrm{f}}$ & $\mathrm{CFC} 12^{\mathrm{f}}$ & CFC $113^{f}$ & $\mathrm{CCl} 4^{\mathrm{f}}$ \\
\hline 36 & 18HU19820228 & 0 & Flag 3 & Flag 3 & ND & 1 & 1 & 1 & 1 & 1.05 & 1 & ND & ND \\
\hline 67 & $316 \mathrm{~N} 20020530$ & 0 & 0 & 0 & ND & 1 & 1 & 1 & 1 & 1 & 1 & 0.9 & ND \\
\hline 79 & 32L919930718 & $\mathrm{NC}$ & $\mathrm{NC}$ & $\mathrm{NC}^{\mathrm{f}}$ & ND & $\mathrm{NC}$ & $\mathrm{NC}$ & $\mathrm{NC}$ & $\mathrm{NC}$ & ND & ND & ND & ND \\
\hline 91 & 34AR19970805 & $\mathrm{NC}^{\mathrm{i}}$ & ND & ND & ND & 1.05 & 1.04 & 1.15 & $\mathrm{NC}$ & 0.95 & 1 & 1 & 1 \\
\hline 116 & 58AA19940203 & 0 & Flag 3 & Flag 3 & ND & Flag 3 & Flag 3 & ND & 1 & ND & ND & ND & ND \\
\hline 119 & 58AA19950217 & 0 & Flag 3 & Flag 3 & Flag 3 & Flag 3 & 1 & $1^{\mathrm{a}}$ & 1 & 1.1 & 1 & 1 & ND \\
\hline 120 & 58AA19961121 & 0 & 0 & 0 & ND & Flag 3 & Flag 3 & Flag 3 & 0.983 & 1 & 1 & ND & ND \\
\hline 121 & 58AA19970225 & 0 & 0 & 0 & ND & Flag 3 & Flag 3 & Flag 3 & 0.987 & ND & $\mathrm{ND}$ & ND & ND \\
\hline 122 & 58AA19980308 & 0 & 0 & 0 & ND & 1 & Flag 3 & 1 & 0.991 & ND & $\mathrm{ND}$ & ND & ND \\
\hline 125 & 58AA20010527 & $0^{\mathrm{i}}$ & 0 & 0 & NA & ND & ND & ND & 1 & 1 & 0.95 & ND & ND \\
\hline 128 & 58GS20030922 & 0 & 0 & 0 & ND & 1 & 1 & 1 & 1 & 1 & $0.95^{\mathrm{h}}$ & ND & ND \\
\hline 133 & 58JH19931106 & 0 & ND & ND & ND & 1 & 1 & 1 & 1 & 1 & 1 & 0.95 & ND \\
\hline 134 & 58JH19940525 & Flag $3^{\mathrm{i}}$ & 0 & +11.6 & ND & 1 & 1 & 1 & 1 & $\mathrm{ND}$ & ND & ND & ND \\
\hline 135 & 58JH19940723 & NC & $\mathrm{NC}$ & ND & ND & $\mathrm{NC}$ & Flag 3 & $\mathrm{NC}$ & 1 & Flag 3 & Flag 3 & Flag 3 & Flag 3 \\
\hline 136 & 58JH19941028 & 0 & ND & ND & ND & 1 & 1 & 1 & 1 & 1 & 1 & 1 & 1 \\
\hline 137 & 58JH19950427 & $0^{\mathrm{i}}$ & Flag 3 & Flag 3 & ND & 1 & 1 & 1 & 1 & ND & $\mathrm{ND}$ & ND & ND \\
\hline 138 & 58JH19951108 & 0 & Flag 3 & Flag 3 & ND & 1 & 1 & 1 & 1 & 1 & 0.95 & 1 & 1 \\
\hline 139 & 58JH19960720 & $0^{\mathrm{i}}$ & ND & ND & ND & 1 & 1 & 1 & 1 & ND & ND & $\mathrm{ND}$ & ND \\
\hline 140 & 58JH19961030 & 0 & ND & ND & ND & 1 & 1 & 1 & 1 & 1 & 1 & 1.05 & 1 \\
\hline 141 & 58JH19970414 & 0 & 0 & 0 & 0.025 & 1 & 1 & 1 & 1 & 1 & 1 & 1 & 1 \\
\hline 142 & 58JH19980801 & 0 & 0 & 0 & 0.02 & 1 & 1 & 1 & 1 & 1 & 1.05 & 1.1 & 1 \\
\hline 143 & 58JH19990615 & $0^{\mathrm{j}}$ & ND & ND & ND & 1 & 1 & 1 & 1 & 1 & 1 & Flag 3 & 1 \\
\hline 144 & $58 \mathrm{JH} 20000527$ & 0 & ND & ND & ND & 1 & 1 & 1 & 1 & 1 & 1.05 & 1 & 0.95 \\
\hline
\end{tabular}

a Secondary quality control described by Olsen (2009a), adjustments are additive $\left(\mu \mathrm{mol} \mathrm{kg}{ }^{-1}\right)$.

${ }^{\mathrm{b}}$ Secondary quality control described by Olsen (2009b), adjustments are additive $\left(\mu \mathrm{mol} \mathrm{kg}{ }^{-1}\right)$.

${ }^{c}$ Secondary quality control described by Velo et al. (2009), adjustments are additive.

d Secondary quality control described by Olafsson and Olsen (2009), adjustments are multiplicative.

e Secondary quality control described by Falck and Olsen (2009), adjustments are multiplicative.

${ }^{\mathrm{f}}$ Secondary quality control described by Jeansson et al. (2009), adjustments are multiplicative.

g This cruise was the 5th and 6th leg of the MT21 cruise, only leg 5 data were included in our analyses.

h These data were included after secondary QC was completed, regardless they were collected on the Norwegian Shelf and there were limited possibilities for secondary QC.

${ }^{\mathrm{i}}$ Only ctdsal values in file, QC carried out on these.

${ }^{\mathrm{j}}$ Systematic offset(s) in bottle salinity due to long storage time prior to analysis, All bottle values flagged 3 and calculations made with CTD salinity values.

The individual cruises are uniquely identified by an EXPOCODE. These identifiers typically consist of two characters identifying the country code of the research vessel, followed by the two-character vessel NODC (National Oceanographic Data Center) code. The last eight characters denote the starting date of the cruise (as YYYYMMDD), For instance 58GS20030922 means that this cruise was conducted on the Norwegian (58) ship G. O. Sars (GS) and that the cruise commenced on 22 September 2009. In a few cases the sailing date was unknown and the EXPOCODE was derived 
Table 2. List of ships included in the CARINA data from the Nordic Seas. Vessels with * were included in the entry "Iceland Sea", and the vessel with ** was included in the "OMEX1NS" entry.

\begin{tabular}{lll}
\hline NODC Ship Code & Ship name & Country \\
\hline $06 \mathrm{MT}$ & Meteor & Germany \\
$18 \mathrm{HU}$ & Hudson & Canada \\
$316 \mathrm{~N}$ & Knorr & USA \\
$46 \mathrm{FR}$ & Arni Fridrikson* & Iceland \\
$58 \mathrm{AA}$ & Håkon Mosby & Norway \\
$58 \mathrm{JH}$ & Johan Hjort & Norway \\
$58 \mathrm{JM}$ & Jan Mayen** & Norway \\
$58 \mathrm{GS}$ & G. O. Sars & Norway \\
NA & Bjarni Saemundson* & Iceland \\
\hline
\end{tabular}

from the date of the first station occupied during the cruise. Table 2 lists the codes and names of the ships involved in Nordic Seas CARINA.

The results of the secondary quality control are summarized in Table 1. There are four possible results: (i) the data can be used as they are, and in this case the adjustment constant (or factor) is 0 (or 1), (ii) the data can be used but we recommend that they are adjusted by the constant or factor given, (iii) we do not recommend that these data are used as they appear too be of too poor quality, this is indicated by "Flag 3", and (iv) no specific recommendation could be given, these have been labelled NC (not considered). The reasoning behind each recommendation other than the first, is provided in this paper for salinity, Falck and Olsen (2009) for oxygen, Jeansson et al. (2009) for CFCs, Olafsson and Olsen (2009) for nutrients, Olsen (2009a) for $\mathrm{TCO}_{2}$, and Olsen (2009b) for TA. These papers also provide additional information such as names of responsible scientists, complete variable listings, references etc. for the different parameters. The recommendations have been applied to the merged data product, and datums that were found to be questionable or bad have been removed in this, but they are retained with appropriate flags ( 3 or 4 ) in the individual cruise files. Occasionally all values of certain parameter obtained during a complete cruise were found to be questionable (option (iii) above), these data have not necessarily been flagged in the individual cruise files, but have been removed from the data product. As mentioned previously, no adjustments have been applied to the data in the individual cruise files. The recommendations for the parameters measured at the 5 cruises in common with the CARINA-ATL were the same as those reached at by the CARINA-ATL group (Tanhua et al., 2009b), the CARINA-AMS and CARINA-ATL data products are therefore consistent. This also brings the CARINA-AMS data product into consistency with GLODAP (Key et al., 2004), since the CARINA - ATL was consistent with this. GLODAP (Global Ocean Data Analysis Program) was a global synthesis focusing on the carbon data collected at the WOCE/JGOFS cruises carried out during the 1990s and prepared a widely used global ocean carbon data product (Sabine et al., 2005). CARINA is complementary to GLODAP, only 3 out of the 188 cruises included in CARINA is also included in GLODAP, and apart from the stations occupied as part of the TTO-NAS of 1981, no Nordic Seas or Arctic Ocean data were included in GLODAP.

The individual cruise tracks are shown in Fig. 3, along with the salinity profiles after application of our recommendations. Again we note the emphasis on the Greenland Sea, only 7 of the 35 cruises did not have any stations in this area.

\section{Analysis approach}

The quality control was comprised of two distinct steps. First the reported measurements were studied in order to identify outliers and obvious errors, i.e. 1st level QC, which mainly involved examination of property-property plots for detection of outliers. Measurements that were outliers, generally in more than one type of plot were flagged questionable (3) or bad (4). These analyses are further described in Key et al. (2009) and Tanhua et al. (2009a). Secondly, the consistency of the data were analysed in a process called secondary QC. These QC procedures were applied on the post-cruise data sets reported by the measurement teams, and are different from the quality assurance (QA) procedures originally carried out by each cruise measurement team in order to ensure sufficient quality as part of the data collection and analysis procedures. The secondary QC was carried out in order to identify biases in the data and to determine any adjustments (additive for salinity, $\mathrm{TCO}_{2}, \mathrm{TA}$ and $\mathrm{pH}$ and multiplicative for nutrients, oxygen and CFCs) in case the bias was significant. Since surface water values of $\mathrm{TCO}_{2}$, nutrients and oxygen, in particular, are highly variable, and specifically for $\mathrm{TCO}_{2}$ affected by anthropogenic $\mathrm{CO}_{2}$ penetration, the secondary QC was mostly carried out using deep data. Hence these analyses assume that any bias is constant at all depths. Given the most likely causes for offsets (biases in reference material (salinity, $\mathrm{TCO}_{2}$, TA), no reference material $\left(\mathrm{TCO}_{2}\right.$, $\mathrm{TA}$ ) and problems with standardisation (nutrients), this is not unreasonable.

Several different consistency analyses were carried out, depending on the variable in question. Each is described in the different papers dealing with the various Nordic Seas data (Falck and Olsen, 2009; Jeansson et al., 2009; Olafsson and Olsen, 2009; Olsen, 2009a, b). However, with a lot of data collected in the central Greenland Sea, the Nordic Seas data were in particular suitable for extensive use of the crossover and inversion approach for evaluating data consistency (Johnson et al., 2001; Tanhua et al., 2009a). Some general issues apply to these analyses and are mentioned here. Firstly, whereas the analysis in most regions evaluates 

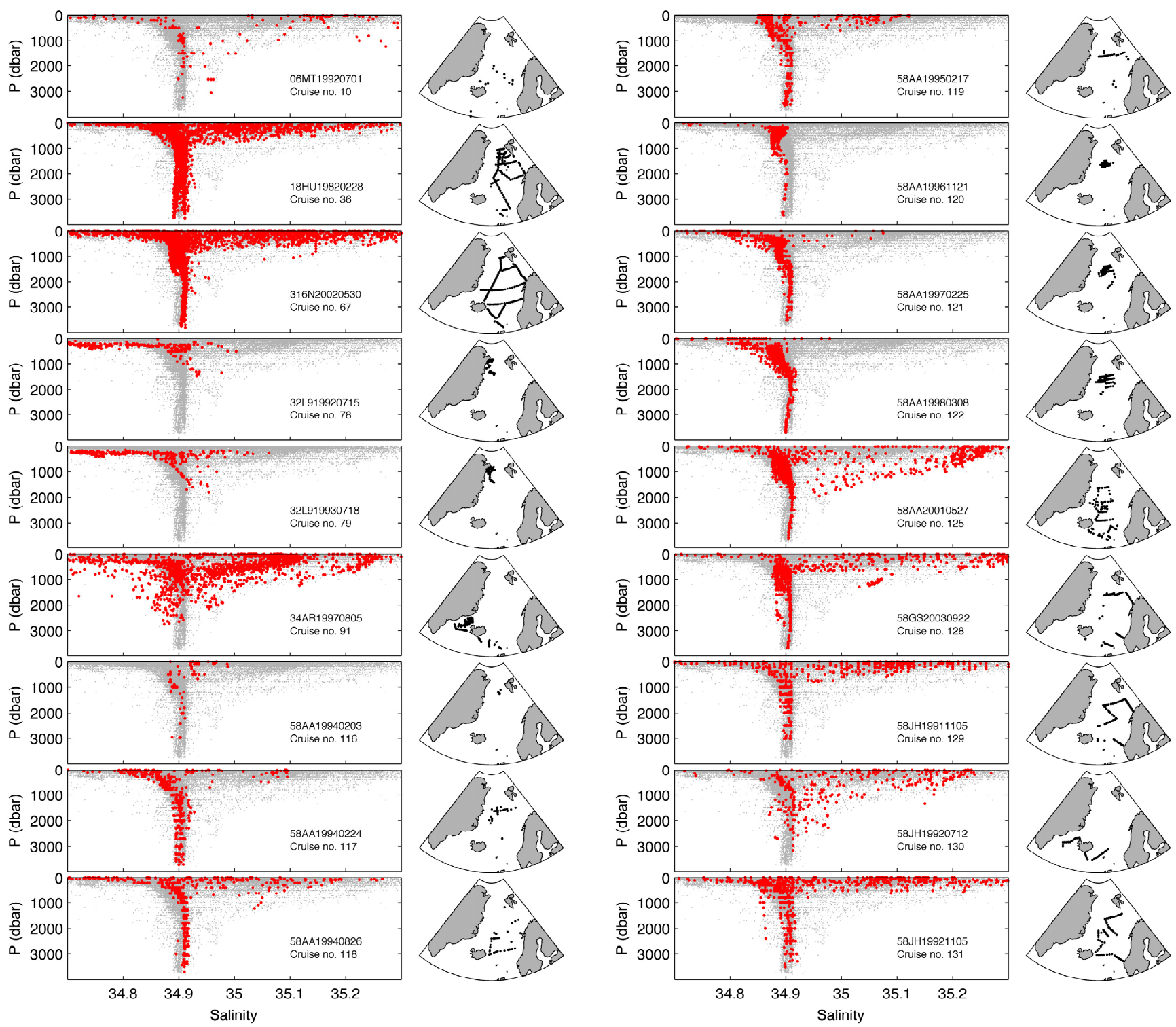

Figure 3. Salinity profiles and station locations for the Nordic Seas CARINA data. All data in collection shown in grey and the specific cruise is shown in red. Note that these are the data with recommendations applied, thus there are no salinity data for 58JH19940525 (134), see Sect. 4.2.2

cruise-to-cruise differences in temperature (Johnson et al., 2001) or density (Tanhua et al., 2009a) space, depth was used as the ordinate in the Nordic Seas due to the small temperature and density gradients in this region, in particular in winter in the Greenland Sea. Secondly, whereas the analysis in most regions is carried out using full depth profiles (Johnson et al., 2001) or data from below $1500 \mathrm{~m}$ (Tanhua et al. 2009a) only samples from deeper than $1900 \mathrm{~m}$ were compared in the Nordic Seas. This was done to ensure that we avoided effects of ventilation, which reached depths of 1600 $\mathrm{m}$ during the 1990s (Ronski and Budéus, 2005). Thirdly, over the last decade there have been clear changes of salinity, silicate, and oxygen in the deep Greenland Sea (Blind- heim and Rey, 2004). These changes are the result of an increasing proportion of deep waters from the Arctic Ocean in this area. Since most of the repeat sampling and therefore crossovers, occurred in the Greenland Sea these trends showed up in the crossover results as well (Sect. 4; Falck and Olsen, 2009; Olafsson and Olsen, 2009). The corrections determined by the inversion of the crossover offsets were therefore not blindly applied on the data, but care was exercised so that any natural trends in the GS would be retained in the final data product. Finally, both manual and automated crossover analyses (Tanhua et al., 2009a) were carried out on all variables, and the agreement between the approaches was excellent. 

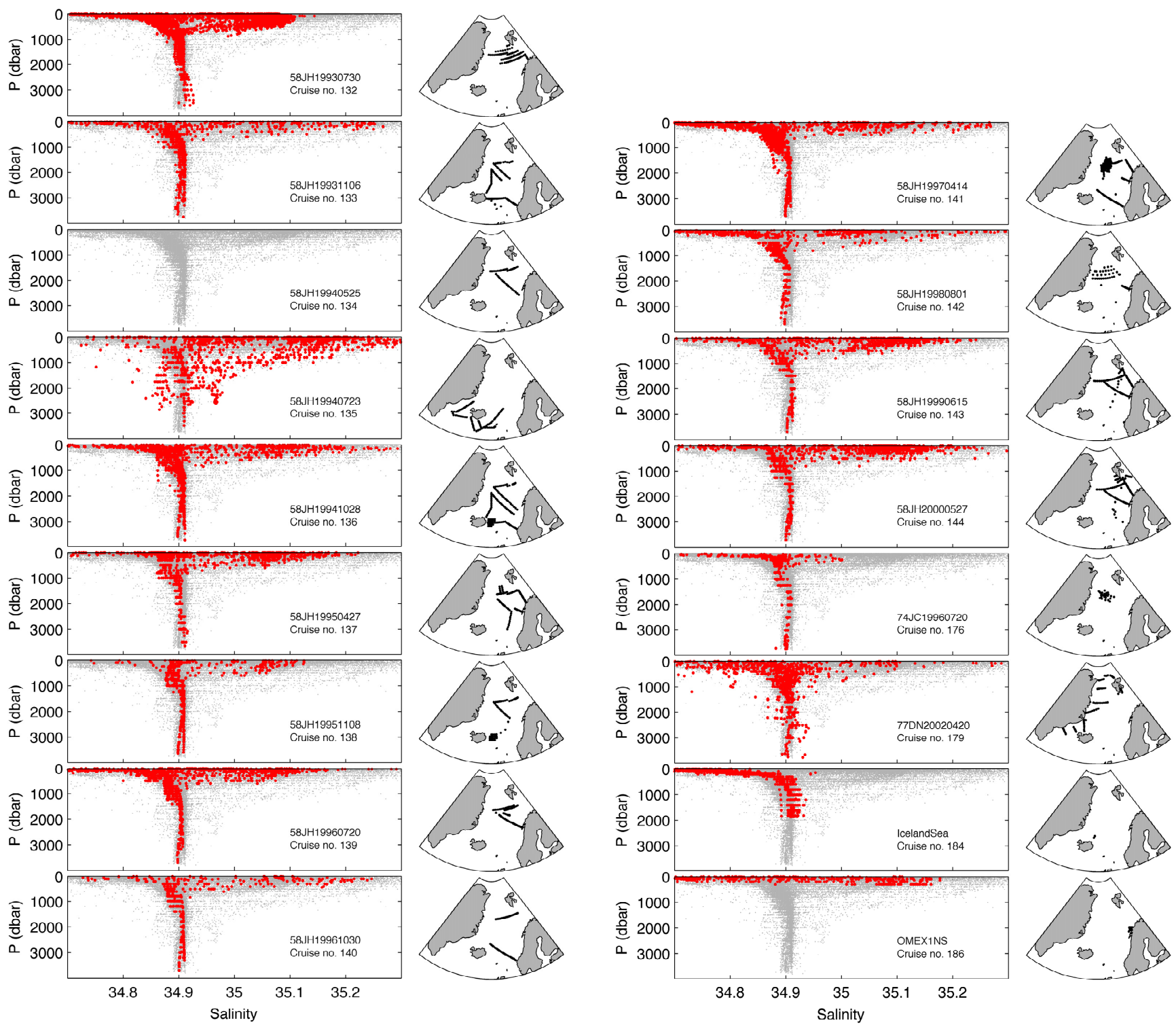

Figure 3. Continued.

\section{Nordic Seas salinity analyses}

In the CARINA database there are two different salinity entries: "salinity" and "ctdsal", where "salinity" refers to salinity measured in discrete samples of water drawn from the water sampling bottle (e.g. Niskin bottle), whereas "ctdsal" refers to salinity measurements derived from the CTD conductivity sensor. It was not possible to unambiguously distinguish between the two for all cruises due to incomplete metadata, and it is almost certain that some ctdsal values have been reported as salinity. During the secondary QC we always used salinity if available, but used cdtsal values if salinity was missing, as indicated by a footnote in Table 1 . Note that the typical differences between salinity and ctdsal (usually a few parts in $\sim 35000$ ) or the differences be-

tween corrected and uncorrected salinity (typically less than 10 parts in 35000 ) are relatively small, but within the cutoff limit of 0.005 salinity units for adjustments to salinity. For most geochemical measurements that require a correction for salinity (through density), these differences do no have any significant impact on the precision of the reported geochemical measurement. Following the salinity QC procedures, the adjustments were either applied to: 1 ) salinity if the secondary QC was solely based on salinity data; 2) ctdsal if the secondary QC was solely based on ctdsal values; or 3) to both salinity and ctdsal if those values were consistent and the secondary QC was based on both parameters. In the merged data product, ctdsal values have been used to fill in gaps in the salinity records. 


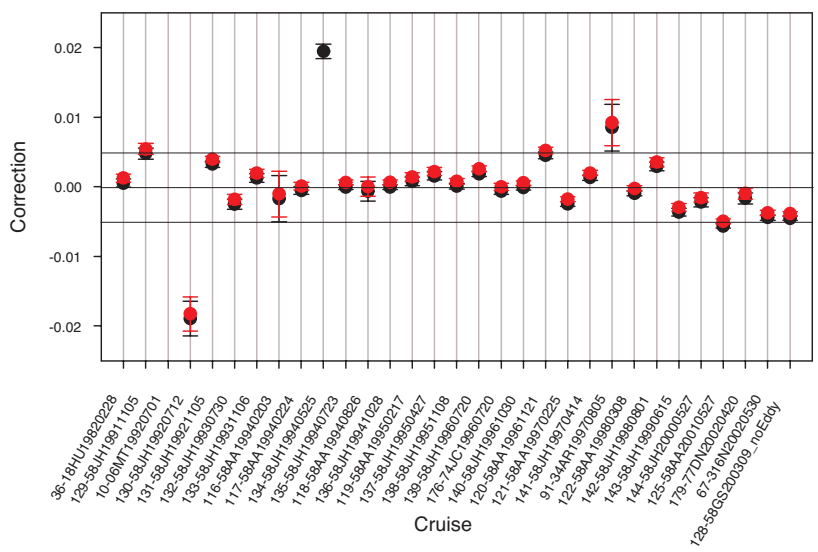

Figure 4. Salinity corrections and their uncertainties from WLSQ inversion of cnaX crossover results (Tanhua et al., 2009a) from data without (black) and with (red) recommendations applied. 58GS20030922 (128) had several stations in a submesoscale coherent eddy (Kasajima et al., 2006), the "_noEddy" signifies that these stations were removed prior to the crossover analysis. Note that cruises have been sorted by date, with oldest cruise to the left.

\subsection{Crossover and inversion analyses}

All results and analyses carried out during the secondary QC of the Nordic Seas salinity data are available at the CARINA website (http://cdiac.ornl.gov/oceans/ CARINA/Carina_inv.html). This section summarises the important findings.

The consistency of the Nordic Seas salinity data was evaluated using an early version of the cnaX crossover routine described by Tanhua et al. (2009a). All station pairs, from different cruises, within $300 \mathrm{~km}$ from each other were defined as crossover points. Thus two cruises may cross over at several points which can over quite large regions with potentially quite different hydrography. This can bias the results. To avoid this, each cruisepair's crossover stations were partitioned into at most 6 clusters, which are groups of stations within a circle of a maximum radius of $175 \mathrm{~km}$, using a kmeans clustering routine (Seber, 1984). A minimum of two stations per cruise was required in each cluster. The data from each station of the two cruises involved in the cluster were interpolated onto $50 \mathrm{~m}$ depth intervals using a piecewise cubic hermite interpolating approach. The interpolated profiles of each cruise were then averaged and an offset and standard deviation profile for each cluster was calculated using data below 1900 dbar. Using these profiles a weighted mean offset and weighted mean standard deviation were determined for each cruisepair and used as input for the inversion that calculated the corrections, following the methodology of Johnson et al. (2001).

The salinity data from Iceland Sea (184), OMEX1NS (186), 32L919920715 (78), and 32L919930718 (79) were not included in this analysis as there were no samples from deeper than 1900 dbar. These data have been labelled NC in Table 1. Figure 4 shows corrections from the Weighted Least Squares (WLSQ, Johnson et al. (2001); Tanhua et al. (2009a)) inversion of the cnaX crossover offsets. Additive corrections have been used and positive values indicate that to obtain consistency an upward correction is required, these data are thus low and vice versa for negative values. Three features are noteworthy: (i) With some exceptions there is an overall trend towards higher salinity values, i.e. increasingly negative corrections. This is consistent with the aforementioned increasing fraction of deep waters from the Arctic Ocean in the deep Greenland Sea where most of the crossovers occurred, and should not be corrected for. (ii) The data from 58JH19920712 (130) appear almost 0.02 too high, those from 58JH19940525 (134) appear almost 0.02 too low, and those from 34AR19970805 (91) appears almost 0.01 too low. These data are thus all more offset than the CARINA wide threshold for applying salinity corrections of \pm 0.005 (Tanhua et al, 2009a). Finally, (iii) at the start and end there is some noise, but within \pm 0.005 when the temporal trend is taken into account.

\subsection{Recommendations}

Given the outcome of the crossover and inversion analysis we believe that the cruises 58JH19920712 (130), 58JH19940525 (134) and 34AR19970805 (91) should be considered for adjustments and are discussed in the following subsections. In addition some special considerations applies to 58JH19940723 (135).

\subsubsection{JH19920712 (130)}

This cruise took place outside the Greenland Sea, mainly through the Denmark Strait and Iceland - Faeroe Gap (see Fig. 3). The number of crossovers with other cruises is therefore limited. Given this and given the variability of this region we feel that we do not have enough evidence to recommend that an adjustment should be applied to these data. To signify this, the salinity data of this cruise have been labelled NC (Not Considered) in Table 1.

\subsubsection{JH19940525 (134)}

The inversion of the crossover results indicated that the data were almost 0.02 too low. This cruise covered the northern Norwegian Sea and Greenland Sea, and it had many crossovers with other cruises. Figure 5 compares the salinity data from this cruise with data from the other cruises in the central Greenland Sea and Lofoten Basin. In the Greenland Sea the bottom salinity of 58JH19940525 (134) appears reasonable, but an offset starts appearing at about $3000 \mathrm{dbar}$ and at 2000 dbar salinity appears $\sim 0.025$ lower than what is normally observed. With some variations this difference is retained to the surface. In the Lofoten basin the deepest 

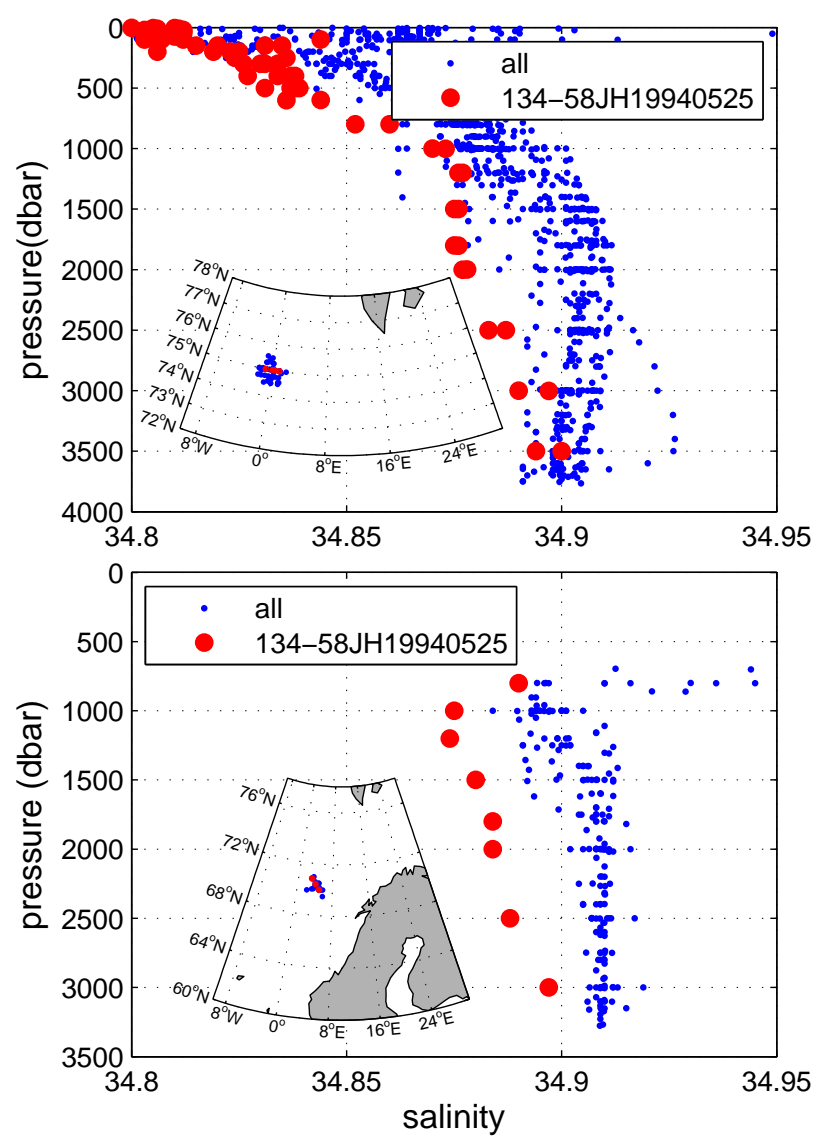

Figure 5. Salinity profiles from (upper) Central Greenland Sea $\left(74.5-75.5^{\circ} \mathrm{N}, 2^{\circ} \mathrm{W}-2^{\circ} \mathrm{E}\right)$ and (lower) Lofoten Basin $\left(69.5^{\circ} \mathrm{N}-\right.$ $\left.71^{\circ} \mathrm{N}, 2-6^{\circ} \mathrm{E}\right)$ obtained at the 58JH19940525 (134) cruise, compared to the other data in the same area. Note that scale has been customised to resolve deep ocean variations and there are surface data not appearing in this figure, as they are off-scale.

data are $\sim 0.015$ lower than what is normally observed. The difference increases moving towards shallower depths, and at 2000 dbar the data are around 0.03 lower than normal. None of the other data obtained at this cruise suggested that an exceptional hydrographic phenomenon was taking place in either of these two basins. We therefore attribute these features to deficiencies of the measurements, but given the variable nature of the offset no robust correction factor can be determined and we feel that the most appropriate recommendation for these data is to label them questionable. The data are therefore not included in the merged CARINA data product.

\subsubsection{AR19970805 (91)}

The crossover and inversion analysis indicated that the salinity data from this cruise were almost 0.01 too low. The cruise took place across the Nordic Seas - North Atlantic overflow regions (Fig. 3) and given the variability here there is a chance that the offset has a natural rather than instrumental cause, and we have chosen to label the salinity data from this cruise NC in Table 1. This is consistent with the decision for the 58JH19920712 (130) salinity data.

\subsubsection{JH19940723 (135)}

The correction determined by the inversion was smaller that the threshold of \pm 0.005 . However, the cruise took place in the same region as 58JH19920712 (130) and 34AR19970805 (91), and for consistency we have chosen to label the salinity data NC in Table 1.

\subsection{Consistency of final Nordic Seas salinity data}

In order to evaluate the consistency of the final Nordic Seas salinity data, a cnaX crossover analysis was carried out after the recommendations were implemented. The corrections determined through the WLSQ inversion of the crossover offsets are shown in Fig. 4. The corrections for the corrected data are all higher than the corrections proposed for the original data. This is a consequence of the practise that the inversion objectively determines the corrections required to maximize the consistency of the cruises, i.e. no a priori assumption on what is the "correct" deep sea salinity value is invoked. By removing the very low cruise 58JH19940525 (134), the remaining cruises becomes overall less positively biased, resulting in a shift to less negative corrections.

With a few exceptions the data are consistent to within \pm 0.005 . The most notable are 58JH19920712 (130) and 34AR19970805 (91), which both took place in the overflow regions and therefore have been labelled NC. Otherwise there appears to be a slight trend in the data, with newer cruises having higher salinities than the older (i.e. newer cruises needing negative adjustments), consistent with the observations of Blindheim and Rey (2004) of increasing salinities in the deep Greenland Sea, where most of the crossovers occurred. Both 58JH19911105 (129) and 58AA20010527 (125) falls just outside the \pm 0.005 consistency limit, but considering the timing we believe that this just reflects the natural variation in the Greenland Sea.

\section{Data access}

The whole CARINA database is published at http://cdiac. ornl.gov/oceans/CARINA/Carina_inv.html. It contains 188 individual cruise files in comma-separated, WHP exchange format. Condensed metadata is contained in the header of each data file. In addition, the CARINA database contains the three merged comma-separated data files with the data products. These files are divided into the three geographical regions of CARINA. The Nordic Seas data presented here are part of the Arctic Mediterranean Seas collection. No special software is needed to access the data, but software for Matlab users is offered to facilitate reading of the data. 
Acknowledgements. This work was carried out with support from the Norwegian Research Council through A-CARB (188167) and CARBON-HEAT (185093), and from EU IP CARBOOCEAN (511176). Additional support from the International Ocean Carbon Coordination Project (IOCCP) and the Hanse Institute for Advanced Study (HWK), Delmenhorst, Germany have been greatly appreciated. Additional support as follows, for R. M. Key, NOAA grant NA08OAR4320752 and NA0OAR4310820; J. L. Bullister, NOAA Climate Program Office. Without the dedication and hard work of all investigators and analysts who collected the data used in this study, this project would not have been possible and we gratefully acknowledge those who have contributed their data to the CARINA project. Comments by two anonymous reviewers helped to clarify this article, which is contribution no. A257 of the Bjerknes Centre for Climate Research.

Edited by: M. Hoppema

\section{References}

Blindheim, J. and Rey, F.: Water-mass formation and distribution in the Nordic Seas during the 1990s, ICES J. Mar. Sci., 61, 846863, 2004.

Brewer, P. G., Takahashi, T., and Williams, R. T.: Transient tracers in the ocean - Hydrography data and carbon dioxide systems with revised carbon chemistry data, NDP-004/R41, Carbon Dioxide Information Analysis Center, Oak Ridge National Laboratory, Oak Ridge, Tenn., USA, 1986.

Bönisch, G., Blindheim, J., Bullister, J. L., Schlosser, P., and Wallace, D. W. R.: Long-term trends of temperature, salinity, density and transient tracers in the Greenland Sea, J. Geophys. Res, 102, 18553-18571, 1997.

Falck, E. and Olsen, A.: Nordic Seas dissolved oxygen data in CARINA, Earth Syst. Sci. Data Discuss., 2, 537-553, 2009, http://www.earth-syst-sci-data-discuss.net/2/537/2009/.

Jeansson, E., Olsson, K. A., Tanhua, T., and Bullister, J. L.: Nordic Seas and Arctic Ocean CFC data in CARINA, Earth Syst. Sci. Data Discuss., 2, 493-536, 2009,

http://www.earth-syst-sci-data-discuss.net/2/493/2009/.

Jeansson, E., Jutterström, S., Rudels, B., Anderson, L. G., Olsson, K. A., Jones, E. P., Smethie Jr., W. M., and Swift, J. H.: Sources to the East Greenland Current and its contribution to the Denmark Strait overflow, Prog. Oceanogr., 78, 12-28, 2008

Johnson, G. C., Robbins, P. E., and Hufford, G. E.: Systematic adjustments of hydrographic sections for internal consistency, J. Atmos. Ocean. Tech., 18, 1234-1244, 2001.

Jutterström, S., Anderson, L. G., Bates, N. R., Bellerby, R., Johannessen, T., Jones, E. P., Key, R. M., Lin, X., Olsen, A., and Omar, A. M.: Arctic Ocean data in CARINA, Earth Syst. Sci. Data Discuss., 2, 281-308, 2009,

http://www.earth-syst-sci-data-discuss.net/2/281/2009/.

Jutterström, S., Jeansson, E., Anderson, L. G., Bellerby, R., Jones, E. P., Smethie Jr., W. M., and Swift, J.: Evaluation of anthropogenic carbon in the Nordic Seas using observed relationships of N, P and C versus CFCs, Prog. Oceanog., 78, 78-84, 2008.

Kasajima, Y., Olsson, K. A., Johannessen, T., Messias, M.-J., Jeansson, E., Bellerby, R. G. J., and Skjelvan, I.: A submesoscale coherent eddy in the Greenland Sea in 2003, J. Geophys. Res., 111, C07013, doi:10.1029/2005JC003130, 2006.
Karstensen, J., Schlosser, P., Wallace, D. W. R., Bullister, J., and Blindheim, J.: Water mass transformation in the Greenland Sea during the 1990s, J. Geophys. Res., 110, C07022, doi:10.1029/2004JC002510, 2005.

Key, R. M., Kozyr, A., Sabine, C. L., Lee, K., Wanninkhof, R., Bullister, J., Feely, R. A., Millero, F., Mordy, C., and Peng, T.-H.: Results from the Global Data Analysis Project (GLODAP), Global. Biogeochem. Cy., 18, GB4031, doi:10.1029/2004GB002247, 2004.

Key, R. M. Tanhua, T., Olsen, A., Hoppema, M., Jutterström, S., Schirnick, C., van Heuven, S., Lin. X., Wallace, D. W. R., and Mintrop, L.: The CARINA data synthesis project: Introduction and overview, Earth Syst. Sci. Data Discuss., in press, 2009.

Olafsson, J. and Olsen, A.: Nordic Seas nutrients data in CARINA, Earth Syst. Sci. Data Discuss., in preparation, 2009.

Olsen, A.: Nordic Seas total dissolved inorganic carbon data in CARINA, Earth Syst. Sci. Data Discuss., 2, 181-203, 2009a, http://www.earth-syst-sci-data-discuss.net/2/181/2009/.

Olsen, A.: Nordic Seas total alkalinity data in CARINA, Earth Syst. Sci. Data Discuss., 2, 309-330, 2009b, http://www.earth-syst-sci-data-discuss.net/2/309/2009/.

Olsen, A., Omar, A. M., Bellerby, R. G. J., Johannessen, T., Ninnemann, U., Brown, K. R., Olsson, K. A., Olafsson, J., Nondal, G., Kivimäe, C., Kringstad, S., Neill, C., and Olafsdottir, S.: Magnitude and origin of the anthropogenic $\mathrm{CO}_{2}$ increase and ${ }^{13} \mathrm{C}$ Suess effect in the Nordic seas since 1981, Global Biogeochem. Cy., 20, GB3027, doi:10.1029/2005GB002669, 2006.

Ronski, S. and Budéus, G.: Time series of winter convection in the Greenland Sea, J. Geophys. Res., 110, C04015, doi:10.1029/2004JC002318, 2005.

Sabine, C. L., Key, R. M., Kozyr, A., Feely, R. A., Wanninkhof, R., Millero, F. J., Peng, T.-H., Bullister, J. L., and Lee, K.: Global Ocean Data Analysis Project: Results and Data, ORNL/CDIAC145, NDP-083, Carbon Dioxide Information Analysis Center, Oak Ridge National Laboratory, U.S. Department of Energy, Oak Ridge, Tennesse, 110 pp., 2005.

Seber, C. A. F.: Multivariate Observations, NJ, John Wiley \& Sons, Inc, 1984.

Tanhua, T., van Heuven, S., Key, R. M., Velo, A., Olsen, A., and Schirnick, C.: Quality control procedures and methods of the CARINA database, Earth Syst. Sci. Data Discuss., 2, 205-240, 2009a, http://www.earth-syst-sci-data-discuss.net/2/205/2009/.

Tanhua, T., Steinfeldt, R., Key, R. M., Brown, P., Gruber, N., Wanninkhof, R., Perez, F., Krtzinger, A., Velo, A., Schuster, U., van Heuven, S., Bullister, J. L., Stendardo, I., Hoppema, M., Olsen, A., Kozyr, A., Pierrot, D., Schirnick, C., and Wallace, D. W. R.: Atlantic Ocean CARINA data: overview and salinity adjustments, Earth Syst. Sci. Data Discuss., 2, 241-280, 2009b, http://www.earth-syst-sci-data-discuss.net/2/241/2009/.

Velo, A., Pérez, F. F., Lin, X., Key, R. M., Tanhua, T., de la Paz, M., van Heuven, S., Jutterström, S., and Ríos, A. F.: CARINA data synthesis project: $\mathrm{pH}$ data scale unification and cruise adjustments, Earth Syst. Sci. Data Discuss., 2, 421-475, 2009, http://www.earth-syst-sci-data-discuss.net/2/421/2009/. 